\title{
Subtidal soft sediments of the Paranaguá Bay inlet: mapping habitats and species distribution at a landscape scale
}

\author{
Orlei Antonio Negrello-Filho ${ }^{1,2 *}{ }^{-}$, Juan Carlos Ugaz-Codina ${ }^{2}$, Luiz Henrique Sielski de Oliveira ${ }^{I}$, \\ Maria Cristina de Souza ${ }^{1}$, Rodolfo José Angulo ${ }^{1}$
}

\author{
${ }^{1}$ Universidade Federal do Paraná, Laboratório de Estudos Costeiros \\ (Av. Cel. Francisco H. dos Santos, 210 - Jardim das Américas - Curitiba - PR - 80060-000 - Brazil) \\ ${ }^{2}$ Benthos - Ciência e Tecnologia em Meio Ambiente Ltda., Laboratório de Ecologia Bêntica \\ (R. Luiz Antonio Biazzetto, 8 - Casa 01 São Lourenco - Curitiba - PR - 82200-050 - Brazil) \\ *Corresponding author: orlei.negrello@gmail.com
}

\section{ABstract}

This study aimed to map habitats and species distribution in a benthoscape section of the Paranaguá Bay inlet, Paraná State, Southern Brazil. The degree of correspondence between maps independently generated through sidescan imagery and macrofauna and sediment samples was also evaluated. The study area had approximately $9 \mathrm{~km}^{2}$ and was chosen considering both diverse landscape features and proximity to future port developments. Sampling was performed in 67 evenly distributed and unreplicated sites. Patterns related to backscatter intensity (high and low) and the presence or absence of bedforms were observed, as well as other large-scale features like sand waves and beach rock outcrops. Local sedimentary environments were represented in a mosaic used for comparisons with sedimentary and faunistic data. Cluster analysis using grain size data formed four groups with similar particle size distribution. A strong correspondence between habitats and grain size distribution was found in only one habitat class. Macrofauna around the deeper Poço Point region and the Mel Island shallower banks presented high species richness and number of individuals. These were considered habitats of high biological relevance. Regions with bedforms indicate higher rates of sand transport in which a few species can thrive. The navigation channel had the lowest number of species and individuals when compared to vicinal regions, indicating persistent impacts. The study evidenced local estuarine bottom heterogeneity and contributed to the understanding of local processes of both bottom sediments dynamics and their associate faunal components.

Descriptors: Seafloor mapping, Sidescan sonar, Regular grid sampling, Estuarine dynamics.

\section{INTRODUCTION}

Seafloor environments of coasts and estuaries reveal a distinctive heterogeneity at many spatial scales (Thrush and Lohrer, 2012). However, this structural diversity is not promptly visible since the presence of the water column blocks sight.

The landscape scale is fundamental to understand the estuarine dynamics (Hewitt et al., 2004). Implementing landscape ecology as a tool to study the aquatic environment involves the development of interpretation methods for sonar images, the proposal of ecological theories applied to the seafloor, and an increase in the

Submitted on: 11/May/2018

Approved on: 19/August/2018

http://dx.doi.org/10.1590/S1679-875920180192406603 number of empirical studies to allow critical evaluation of theories (Zajac, 2008).

Sedimentary environments encompass a significant proportion of benthic habitats and are defined by geomorphological features and sedimentary properties (Zajac, 2008). Some studies argue that the term 'habitat' is not a strictly delimited concept and can be used to describe a range of different attributes at different spatial and temporal scales (Brown et al., 2011; Costello, 2009). Herein habitat is equated to sedimentary environments, that is, habitats are seabed patches with distinct physical characteristics. The concept was purposefully restricted to not overlay with 'niche', which is well established and incorporates a higher number of biotic and abiotic variables. The term habitat is used in a geographical perspective, in which spatial coordinates can be applied, and boundaries can be defined. 
Analysis of geomorphological patterns can identify predominant long-term processes at a scale of years and even decades, including sand transport, erosion, and fine particle deposition. One of the most successful tools for mapping the seafloor is the sidescan sonar, which produces continuous seafloor images in high definition through emission and reception of repeated acoustic signals.

Some approaches have been proposed to produce habitat maps; most of them interpret the continuous coverage of sonar data and use in situ sampling of ground truth and observation of the seabed for validation, in a top-down approach (Brown et al., 2011). The comparisons should be straightforward when the sediment data are used for validation since backscatter intensity is directly related to seabed geophysical properties. On the other hand, it has been challenging to explain distribution patterns of macrofauna as a function of seafloor habitats. The macrofauna species present a vast range of adaptations and life-history strategies, with different degrees of mobility and amplitude of occurrence. These species seem not to properly correlate with mean grain size and other granulometric parameters (Snelgrove and Butman, 1994).

Species distribution maps have been widely used in ecological research, even when not necessarily correlating with other environmental parameters (Künitzer et al., 1992). These biological maps can be population-centered, i.e., focused on the spatial distribution of single species or community-centered, when a whole assemblage is taken into account, usually focusing on a few, the most representative species.

A fundamental biological attribute of sedimentary environments is population density. High numbers of individuals per unit area are a predicate for accomplishing ecological services (Braeckman et al., 2010; de Backer et al., 2011). Some species act as ecosystem engineers by providing resources and even habitat for other populations. When keystone species of ecosystem engineers are present the production increases, and food webs become more intricate (Mermillod-Blondin and Rosenberg, 2006). As a general rule, regions with high biodiversity (Hooper et al., 2005) and/or the presence of ecosystem engineers in high densities (Crain and Bertness, 2006) are the most relevant for conservation.

Besides helping to uncover benthic dynamics, seafloor maps are useful to manage benthic habitats and to delimit protected areas and resources. 'In this context, the goal of this study was to map habitats and species distribution in a benthoscape section of the Paranaguá Bay inlet.'

\section{MATERIAL AND METHODS}

\section{STUDY AREA}

The present study was conducted in an area of 8.2 $\mathrm{Km}^{2}$ of the Paranaguá Bay inlet, a place where port developments are starting to take place. The bay is situated in a more extensive estuarine complex in the Paraná State, Southern Brazil (Figure 1). Two prominent geographical features can be seen in the nautical chart, a depression $25 \mathrm{~m}$ in depth located southwest resulting from natural flow patterns and a dredged navigation channel oriented southeast to northwest, crossing the middle of the study area (Figure 1). The region is considered euhaline with average salinity $\sim 30 \%$ and temperature range of $23^{\circ} \mathrm{C}-30^{\circ} \mathrm{C}$ (Lana et al., 2000). Tidal currents are semidiurnal with the highest amplitudes around $1.8 \mathrm{~m}$ during spring tides, characterizing a microtidal environment (Noernberg et al., 2007).

\section{SIDESCAN SONAR}

The survey was performed using a $680 \mathrm{kHz}$ Deep Vision towed two-three knots connected to a Garmin $60 \mathrm{CSx}$ GPS, at approximately $1 \mathrm{~m}$ below the water line. Navigation tracks reached $120 \mathrm{~m}$ in width, with approximately $30 \%$ of superposition between following tracks. Tracks were roughly parallel to the main water flow. Although the sea conditions were not optimal during the three days in the field, the data were reasonable thus allowing interpretation.

Images were processed and ordered using DeepView SE v4.1 (Deep Vision Research \& Development Sonar Systems, Linköping, Sweden) to obtain a map with bottom relief at a landscape scale. Patterns related to backscatter intensity (high and low) and the presence or absence of bedforms (at the scale of meters) were delimited, as well as other large-scale features, including sand waves, subaqueous dunes, and beach rock outcrops. Local sedimentary environments were represented in a mosaic (Figure 1), which was later used as a bottom layer for superimposing sedimentary data. The final mosaic output was printed in enhanced quality $(2 \mathrm{~m} \times 2 \mathrm{~m})$, allowing the interpretation of large-scale patterns.

\section{SEDIMENTARY ANALYSIS}

Superficial sediment samples were collected at 67 sites located on a regular grid with a Van Veen grab $\left(0.025 \mathrm{~m}^{2}\right)$ (Figure 1). Only valid samples were used, i.e., those that recovered a minimum of $1 \mathrm{~kg}$ of sediments and showed 


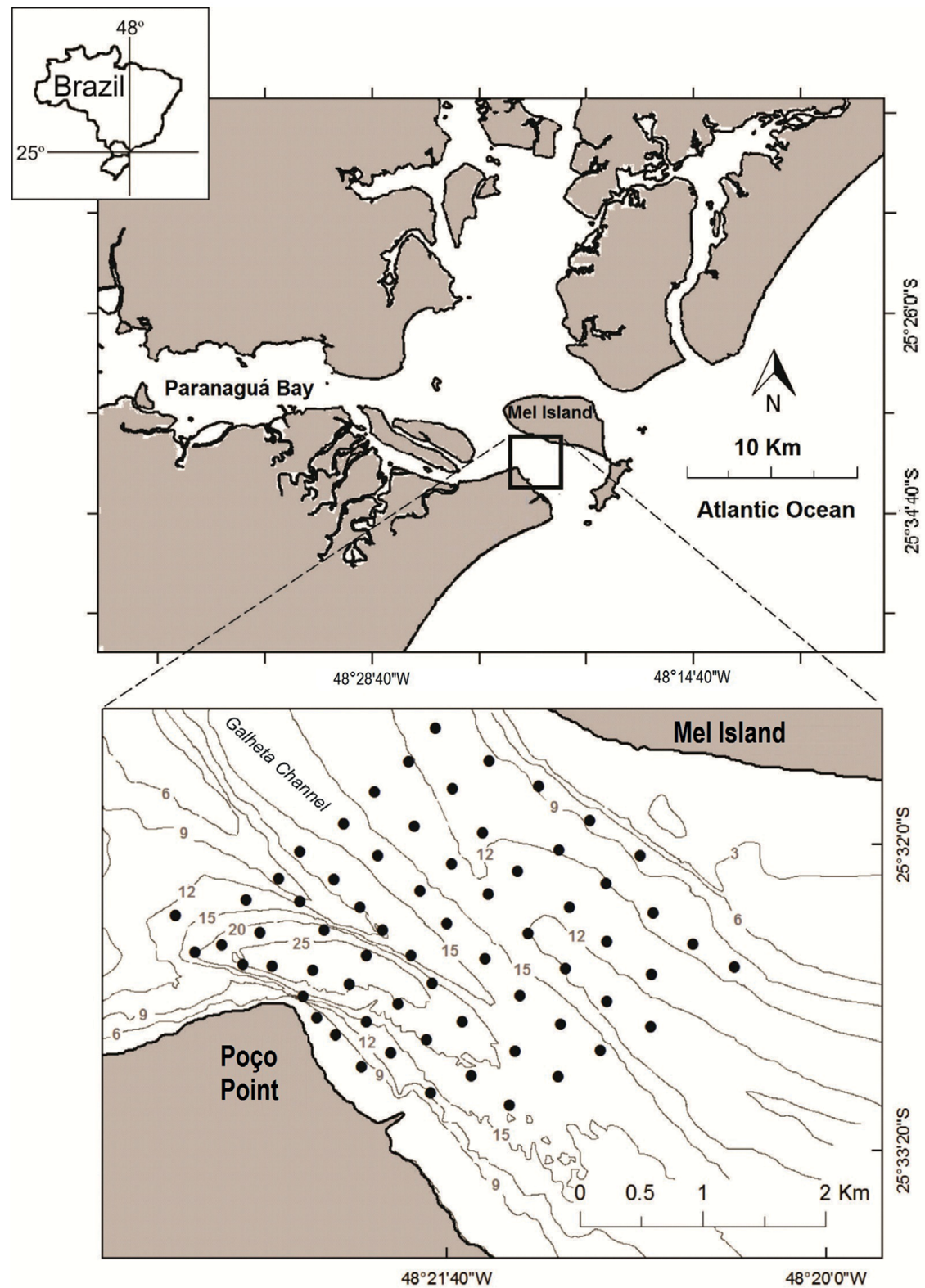

Figure 1. Map of the Paranaguá Bay inlet, Paraná State, Southern Brazil, with the samples grid. The isobaths are provided in meters.

no signs of being washed during sampling. Besides, care was taken to collect the core of the samples that were not in contact with the internal parts of the grab sampler. A single sample was collected per site. Samples were kept on ice for preventing organic matter decomposition. In the laboratory, they were divided for granulometric, organic matter, and carbonate content analyses.

Grain-size analyses were performed by sieving for fractions from sand to gravel $(>0.063 \mathrm{~mm})$ (Folk, 1965) and by the pipette method for finer fractions $(<0.063 \mathrm{~mm})$ (Carver, 1971). Grain-size parameters were obtained by the logarithmic method of Folk and Ward (1957). Organic matter and carbonate contents were analyzed by weight loss on ignition (Davies, 1974) and by acid leaching (Milliman, 1974), respectively. Cluster analysis of grain size data provided groups with similar particle size distribution (Clarke, 1993). Groups were plotted against the mosaic of sedimentary environments to verify the cooccurrence of sediment and bedform types. 


\section{MACROFAUNA}

Macrofauna samples were collected in the same 67 -site grid. Here, a larger van Veen grab $\left(0.032 \mathrm{~m}^{2}\right)$ was used. Soon after, recovery samples were photographed before and after being sieved through a $0.5 \mathrm{~mm}$ sieve. Photographs were used for qualitative assessment of shell fragments and mud clast content. The residue was fixed by adding an $8 \%$ formalin solution to the samples. In the laboratory, samples were sorted, and specimens were counted and identified to the lowest possible taxonomic level.

The metrics richness, density, and frequency of occurrence were used for comparisons. Results of richness and density were plotted against bathymetry for interpreting spatial distribution patterns.

\section{RESULTS}

\section{SidESCAN SONAR MOSAIC AND GEOMORPHOLOGY}

Four geomorphological features were identified in the study area, 1) three tidal channels, 2) a local depression, 3) a subaqueous shoal, and 4) tidal channel shallow marginal areas. The Galheta Channel is an artificial dredged and the main ebb tidal channel of the Paranaguá Bay located in the center of the study area with depths around $15 \mathrm{~m}$. A marginal $12 \mathrm{~m}$ deep channel is located northeast of the Galheta Channel. In the Poço Point region, a secondary $15 \mathrm{~m}$ deep ebb tidal channel is associated to the Poço Point depression, which is a $20 \mathrm{~m}$ deep local depression. A subaqueous shoal divides the Poço Point and Galheta channels. Shallow marginal areas, shallower than $9 \mathrm{~m}$, surround the three tidal channels mentioned above. These morphological features showed different patterns in sidescan imagery.

Four major patterns were identified analyzing sidescan sonograms (Figure 2) represented as a combination of backscatter intensity with the presence or absence of bedforms (Figure 3). These patterns correspond to local variations of morphological features described above. Both the Galheta Channel and the Poço Point channel showed low backscatter and no bedforms. The regions near the Poço Point local depression showed low backscatter but apparent bedforms. A considerable part of the margins of the tidal channels was characterized by high backscatter response, mostly with bedforms. Marginal areas of the tidal channels and subaqueous shoals are represented by few pockets of high backscatter, with no bedforms, scattered in the study area (Figure 2).

\section{SEDiments}

The surveyed area is mainly composed of well-sorted fine sands with low organic matter and carbonate contents. A total of $61 \%$ of sediments were classified as moderately well to very well-sorted. Mean grain size varied from very fine to coarse sand, with fine sands covering $48 \%$ of the surveyed area, and medium sands covering $15 \%$ (Figure 4). Organic matter and carbonate contents were usually low, with organic matter ranging from $0.15 \%$ to $11.42 \%$, and carbonates from $0.01 \%$ to $23.78 \%$. The mean values were $1.21 \%$ and $3.13 \%$, respectively. Organic matter and carbonate contents were not directly related to grain size. Sediments of mean grain size of fine sand had the highest and lowest values of organic matter and carbonate content (Figure 4). Sediment classes were determined by grain size parameters.

Cluster results show the arrangement distributed in four main classes (Figure 5), as follows: a) poorly-sorted medium sand with bimodal distribution due to the mixing of two grain populations, one mainly constituted by quartz and the other by shell fragments, from two sites located near beach rock outcrops; b) poorly-sorted medium sand with unimodal distribution, co-occurring with high backscatter and without bedforms; c) medium to fine sand with unimodal distribution associated with high backscatter, with or without bedforms; and d) well-sorted fine sand with unimodal distribution dominating a significant portion of the study area (Figure 5).

Distributions of mud matrix, mud clasts, and shell fragments were not straightforwardly associated with the mosaic of habitats (Figure 6). Nevertheless, mud clasts appear to occur preferentially in places without shell fragments.

\section{FAUNA}

The local macrofauna was composed of small polychaetes, crustaceans, mollusks, cephalochordates, cnidarians, and other less abundant taxa (Table 1). The highest number of organisms was located around the Poço Point region and near the Mel Island banks. The number of species somewhat followed the same tendency (Figure 7). The Galheta Channel presented a very low number of species and densities (Figure 7).

The distribution of most species was not associated with particular habitats. The patterns of occurrence varied according to density, life history strategies, and habitat preferences. A few species displayed geographical preferences, like Branchiostoma sp. (Cephalochordata) 

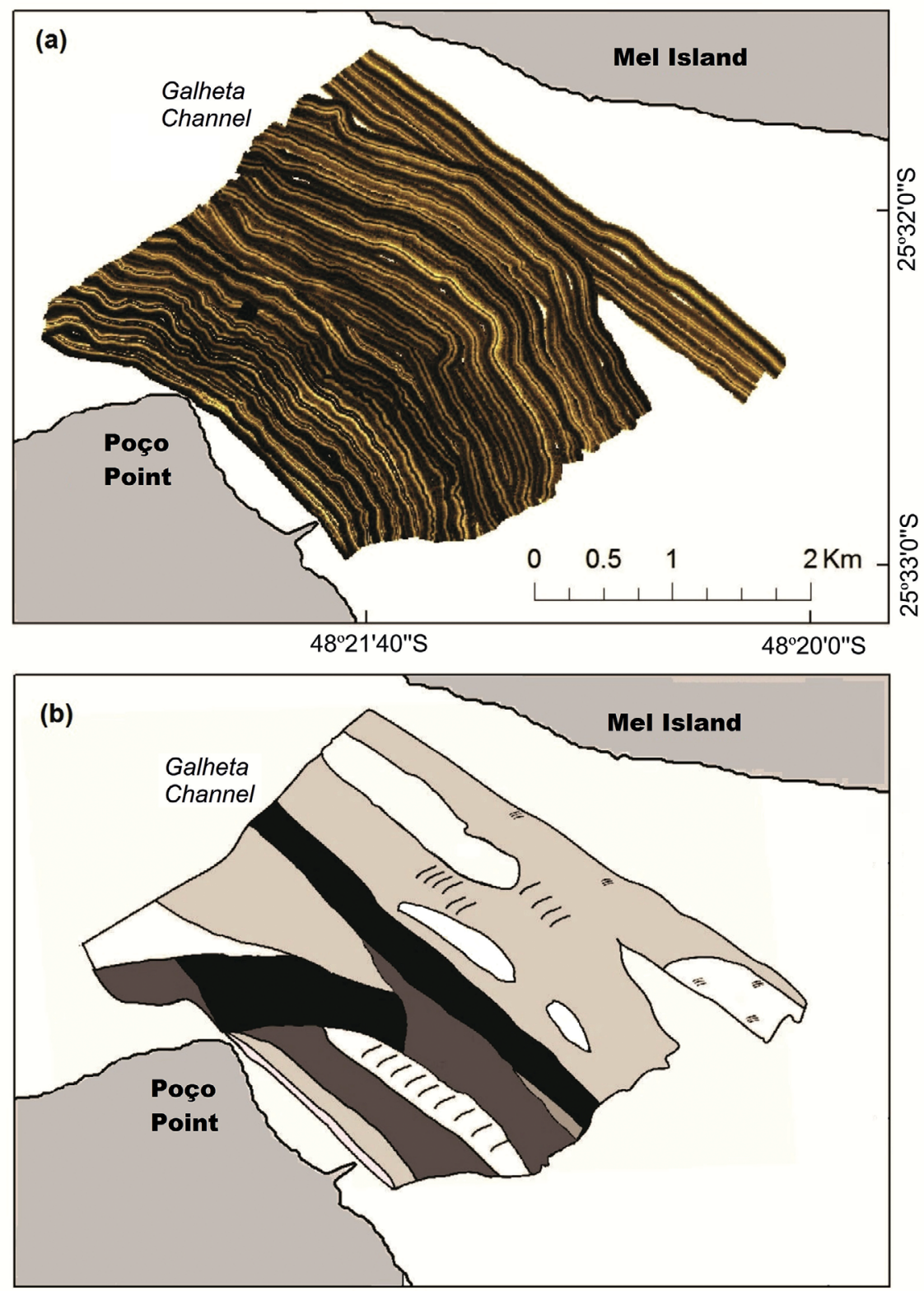

High backscatter intensity without bedforms

High backscatter intensity with bedforms

?/. Sandwaves
Low backscatter intensity with bedforms

Low backscatter intensity without bedforms

* Beachrock outcrop

Figure 2. a) Sidescan record of images in the Paranaguá Bay inlet, Paraná State, Southern Brazil. (b) Interpretation of benthoscape elements according to backscatter intensity and presence or absence of bedforms.

that was found on the northern side and Polygordius sp. (Polychaeta), found in the deeper region of the study area (Figure 8). Cirratulidae 2 (Polychaeta) and Cyrtopleura sp. (Bivalvia) occurred at a single site with high densities, while Microphoxus uroserratus (Amphipoda) and Allia sp. (Polychaeta) were widespread throughout the study area (Figure 8). The remaining taxa were scattered around with low densities (Figure 8). 

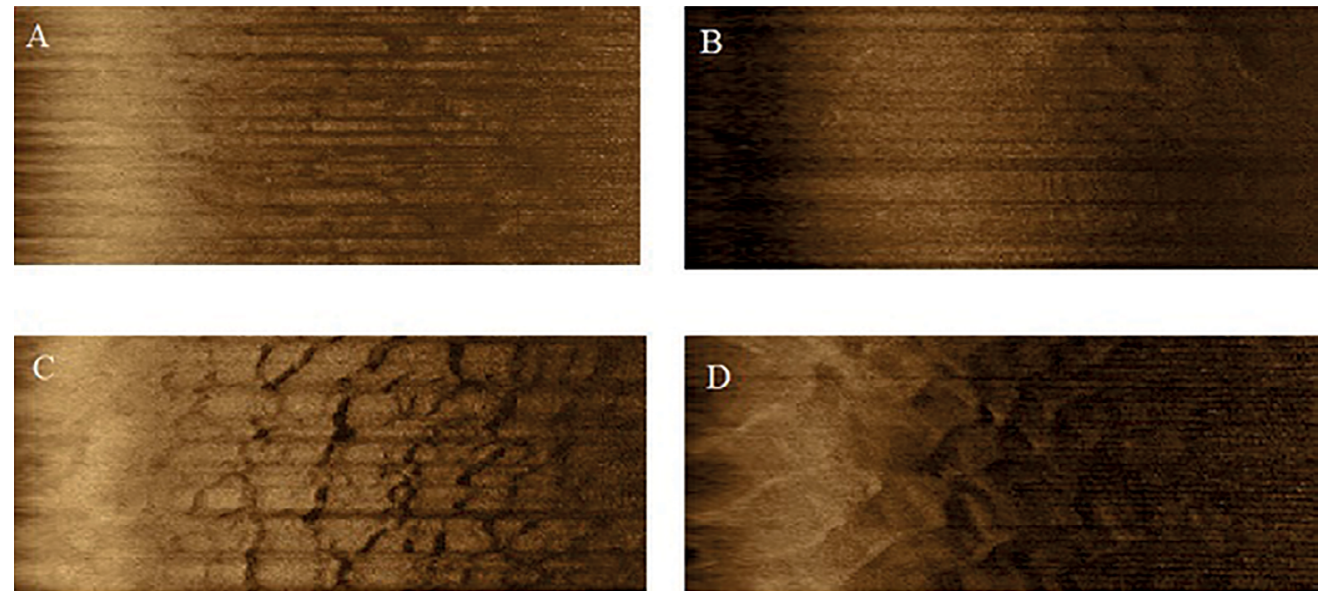

Figure 3. Sidescan track sections of the Paranaguá Bay inlet, Paraná State, Southern Brazil, with examples of the combination of backscatter strength and the presence or absence of bedforms. a) High backscatter/no bedforms. b) Low backscatter/no bedforms. c) High backscatter/with bedforms. d) Low backscatter/with bedforms.
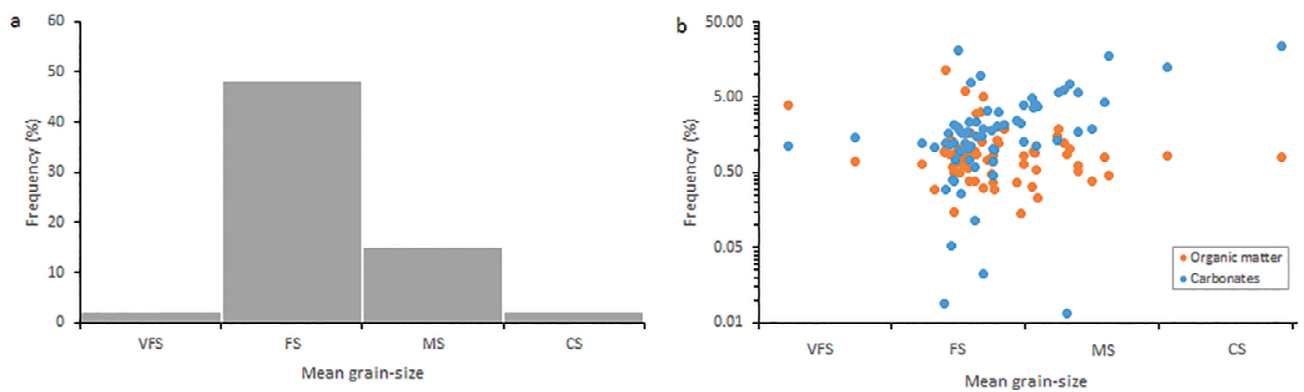

Figure 4. Sedimentological parameters overview. (a) Frequency of mean diameter classes. (b) Relationship between contents of organic matter and carbonates and mean grain size. (VFS, very fine sand; FS, fine sand; MS, medium sand; CS, coarse sand).

Concerning the frequency of occurrence, the most distinctive pattern was observed in regions of high backscatter without bedforms, with a specific assemblage (Table 1), mainly composed of small crustaceans (amphipods, mysidaceans, isopods), syllids, and amphioxus. The other three types of habitat had two more common species (M. uroserratus (Amphipoda) and Allia sp. (Polychaeta)) and other less frequent, like Nephtys sp. (Polychaeta), Nemertea, Cirratulidae (Polychaeta), and Apoprionospio sp. (Polychaeta) (Table 1).

\section{DISCUSSION}

In this study, two sources of data were used to reach a tentative habitat map. A method was proposed based on the integration of independent sediment samples superposed to a mosaic of sedimentary habitats interpreted from sonar results. Backscatter reflection is a function of sediment physical properties (Collier and Brown, 2005); thus, it is reasonable to expect a direct correspondence between them. Many studies have recognized that macrofauna does not necessarily correlate with sedimentary parameters (see review in Snelgrove and Butman, 1994) and habitat types. Considering this statement and the present findings, this study did not attempt to integrate sonar, sediment, and fauna in a single habitat map, even though recent propositions have incorporated environmental variables and species tolerance and preferences to the habitat concept (Diaz et al., 2004; Shumchenia and King, 2010).

The broadening beyond geographic boundaries would approximate habitat to the niche concept, which is species centered. For this reason, in this study habitat is considered a patch of landscape or benthoscape with distinct geophysical characteristics. Usually, authors who were able to join habitats and species distribution worked on larger spatial scales, where the possibility of finding diverse habitat types increases (Kostylev et al., 2001). 

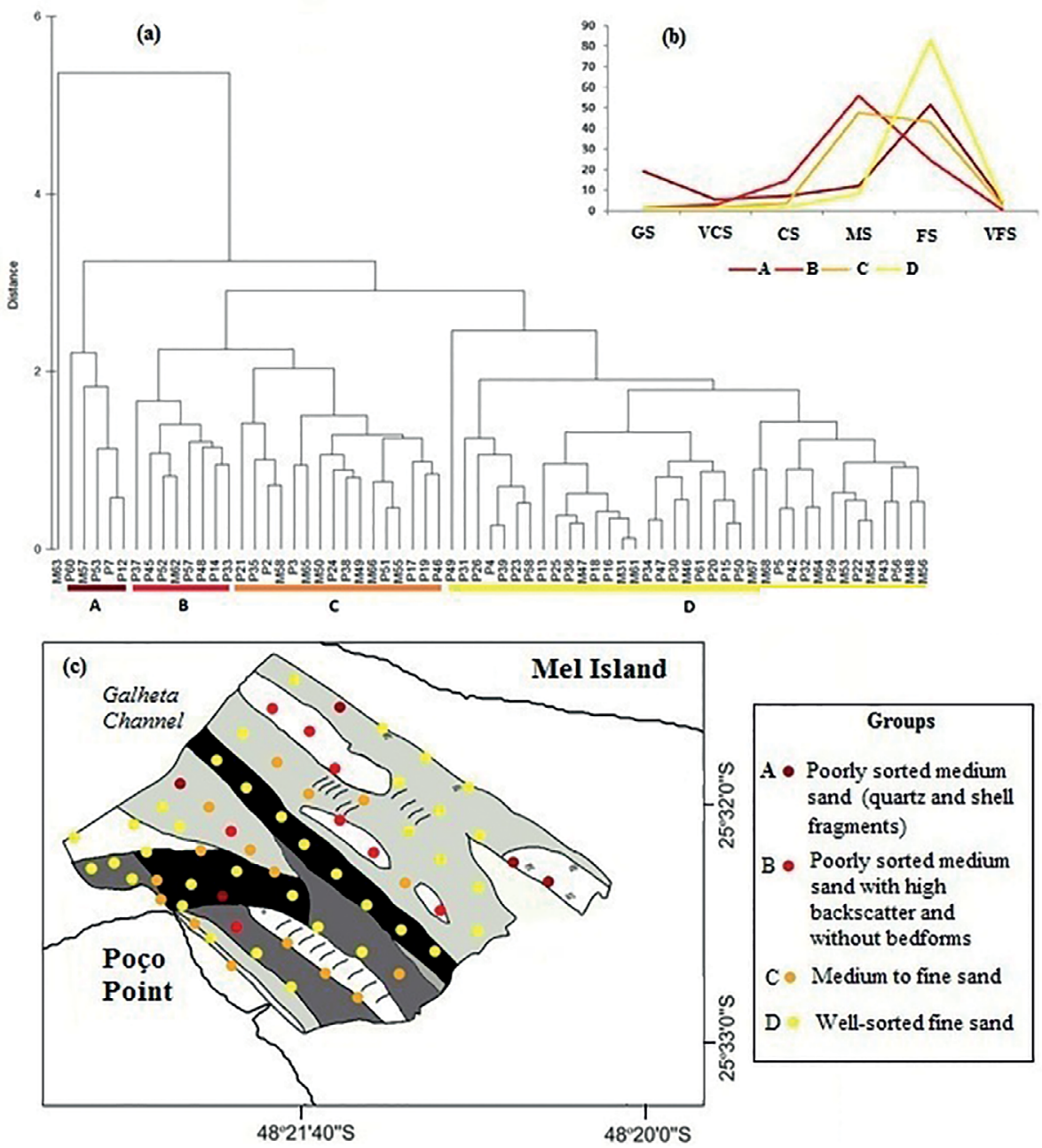

Figure 5. a) Cluster analysis with four groups of samples (Euclidian distance, transformed $\log (\mathrm{x}+1)$ ). b) Histograms with the mean percentage of grain sizes per group of samples (GS, granules; VCS, very coarse sand; CS, coarse sand; MS, medium sand; FS, fine sand; VFS, very fine sand). c) Spatial distribution of sediment samples over the mosaic of habitats.

\section{ACOUSTIC DATA AND SEDIMENT}

Recent results reiterate that the strength of acoustic backscatter is strongly correlated with geophysical properties of bottom substrates (Collier and Brown, 2005; Ferrini and Flood, 2006; Brown and Collier, 2008). In the present study, the most straightforward correspondence between sedimentary environments (interpreted as a mosaic) and sediment samples was obtained in class B, where patches of coarser sediments were associated with high backscatter and no bedforms. On the other hand, the most widespread class D, composed of well-sorted, fine sand, occurred both on high and low backscatter regions.

At first glance, this result may seem disparate since it goes against the reflectance principles established by geophysical studies (Briggs et al., 2002). The lack of correspondence might be related to the lateral range of sidescan acoustic beam and the abrupt changes in seabed depth during acquisition of sonograms. When the lateral range is wide (about $100 \mathrm{~m}$ in this study), and water depth is shallow, the backscatter is high in the central part of the sonogram and low in the borders. Similarly, when the depth increases and the sidescan beam width is kept, the sonograms present lower backscatter intensity. The observed low backscatter in the Galheta Channel and deeper Poço Point region, which are also the most indepth sites in the study area, might be reflecting these changes in water depth. Moreover, the sampling was restricted to calm weather and slack water conditions, when bedload transport is nearly zero. A thin layer of fine sand, transported as bedload or even suspended load, may cover these frequently disturbed regions. 


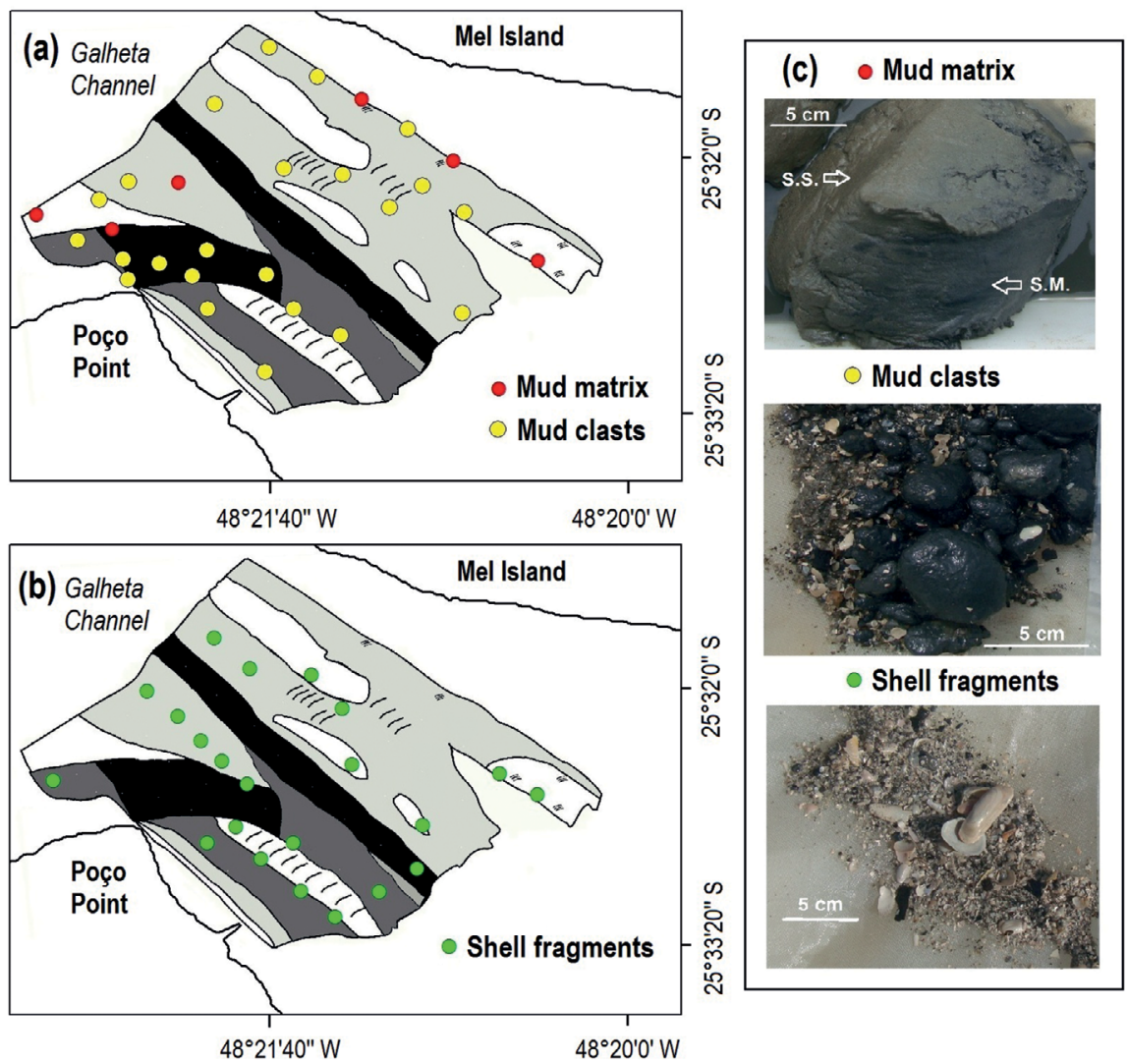

Figure 6. a) Distribution of mud in the form of clasts or matrix, b) shell fragments in the study area, and c) Pictures of the mud matrix (SS, sediment surface and SM, sediment matrix) and residuals of mud clasts and shell fragments after sieving on a $0.5 \mathrm{~mm}$ sieve.

\section{FAUNA}

The intense dynamics of the inlet, with strong tidal currents (Noernberg et al., 1997; Noernberg et al., 2007) acting on the bottom may passively transport macrofauna specimens across habitats (Negrello Filho et al., 2006). Species must be adapted to this fast-changing environment to survive, reproduce, and efficiently colonize preferable habitats. Individuals may still thrive in less favorable habitats for some time, but high densities are not likely to occur. For example, Polygordius sp. was found on a few sites with densities no higher than 30 individuals. During a monitoring study previously developed by one of the authors (Negrello Filho, unpublished data) near the present study area, densities up to a thousand individuals per core sample were observed in a single site, where the sediment was practically dominated by organic matter in the form of relict woody twigs and branches. The same reasoning can be applied to Cyrtopleura sp. and Cirratulidae 2, where scarce, small-scale habitats sustain high densities.

The high density of Cirratulidae 2 (Polychaeta) near beach rock outcrops suggests that these individuals are benefiting from the apparent stability of sediments around this region. The same could be said about Cyrtopleura sp. (Bivalvia), which colonized a distinct sedimentary environment at the deeper Poço Point region. An opposite strategy was observed for Microphoxus uroserratus (Amphipoda) and Allia sp. (Polychaeta), which were present in all habitat types.

Macrofauna distribution showed two areas with the highest species richness and number of individuals; the deeper Poço Point region and the northeastern and shallower region, close to the Mel Island. On the other hand, the Galheta Channel had the lowest numbers. No direct correspondence was found between fauna and habitat type in most of the study area except for the group B (poorly-sorted sand), which presented a specific assemblage, composed mostly of small crustaceans and Syllidae polychaetes. Usually, the infauna is considered as having low mobility, but many of the most representative species in this study are moderate to highly wandering. The combination of high mobility, strong currents, and bedload transport 
Table 1. Frequency of occurrence (FO) of macrofauna species in regions with high and low backscatter and with or without bedforms in the Paranaguá Bay inlet, Paraná State, Southern Brazil.

\begin{tabular}{|c|c|c|c|}
\hline High backscatter- without bedforms & FO (\%) & High backscatter- with bedforms & FO $(\%)$ \\
\hline Microphoxus uroserratus - Amphipoda & 75 & Microphoxus uroserratus - Amphipoda & 68 \\
\hline Syllidae - Polychaeta & 50 & Allia sp. - Polychaeta & 60 \\
\hline Eudevenopus sp. - Amphipoda & 50 & Branchiostoma sp. & 52 \\
\hline Resupinus coloni - Amphipoda & 50 & Apoprionospio sp. - Polychaeta & 40 \\
\hline Mysidacea & 50 & Cnidaria & 36 \\
\hline Branchiostoma sp. & 50 & Cirratulidae 1 - Polychaeta & 36 \\
\hline Excirolana sp. - Isopoda & 44 & Armandia hossfeldi - Polychaeta & 32 \\
\hline Cnidaria & 38 & Eudevenopus sp. - Amphipoda & 32 \\
\hline Allia sp. - Polychaeta & 38 & Resupinus coloni - Amphipoda & 32 \\
\hline Nemertea & 31 & Nephtys sp. - Polychaeta & 28 \\
\hline Low backscatter- without bedforms & FO (\%) & Low backscatter- with bedforms & FO (\%) \\
\hline Microphoxus uroserratus - Amphipoda & 59 & Allia sp. - Polychaeta & 67 \\
\hline Allia sp. - Polychaeta & 35 & Microphoxus uroserratus - Amphipoda & 56 \\
\hline Nephtys sp. - Polychaeta & 35 & Nephtys sp. - Polychaeta & 44 \\
\hline Cnidaria & 24 & Nemertea & 33 \\
\hline Nemertea & 24 & Cirratulidae 1- Polychaeta & 33 \\
\hline Apoprionospio sp. - Polychaeta & 24 & Mysidacea & 33 \\
\hline Cirratulidae 1 - Polychaeta & 24 & Nucula sp. - Bivalvia & 33 \\
\hline Resupinus coloni - Amphipoda & 24 & Armandia hossfeldi - Polychaeta & 22 \\
\hline Mysidacea & 24 & Scoloplos ohlini - Polychaeta & 22 \\
\hline Tanaidacea & 24 & Tanaidacea & 22 \\
\hline
\end{tabular}
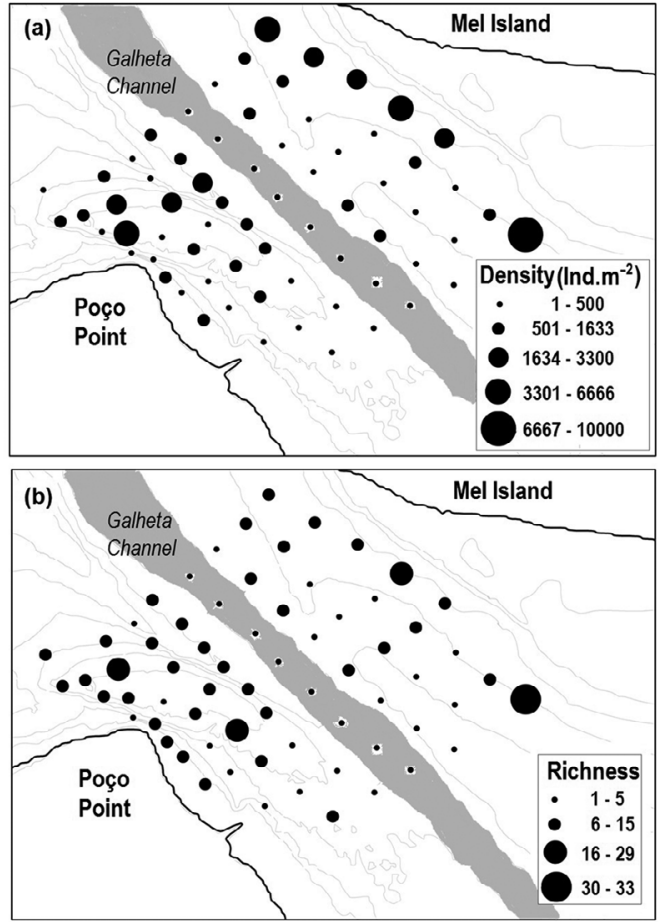

Figure 7. Spatial distribution of a) macrofauna species density and b) richness in the Paranaguá Bay inlet, Paraná State, Southern Brazil. indicate the possibility of a frequent rearrangement of individuals and populations, with a selection of preferred habitats. Moreover, the reduced number of larger species may indicate recruitment limitations due to bottom instability.

The spatial distribution of macrofauna species exhibited several patterns. Some species, like the polychaete Allia sp. and the amphipod $M$. uroserratus, occurred throughout the study area, in virtually all habitats. On the contrary, Cirratulidae 2 and Cyrtopleura sp. occurred in a single site and in very high densities. Both species are associated with benthoscape features at smaller scales. The cirratulid polychaetes were strongly associated to the beach rock outcrop region (at the scale of meters) while the bivalve Cyrtopleura sp. was found in the deeper Poço Point region, boring in hard mud outcrops (the van Veen grab brought a piece of this substrate) that were not evident in sidescan images.

From a biological perspective, when mapping species distribution, two questions emerge. The first is related to the occurrence of species (Which species occur in the study area?); and the second aims at the description of spatial distribution (Where do species occur?). Regular grid design is appropriate to tackle both questions by spreading sampling 

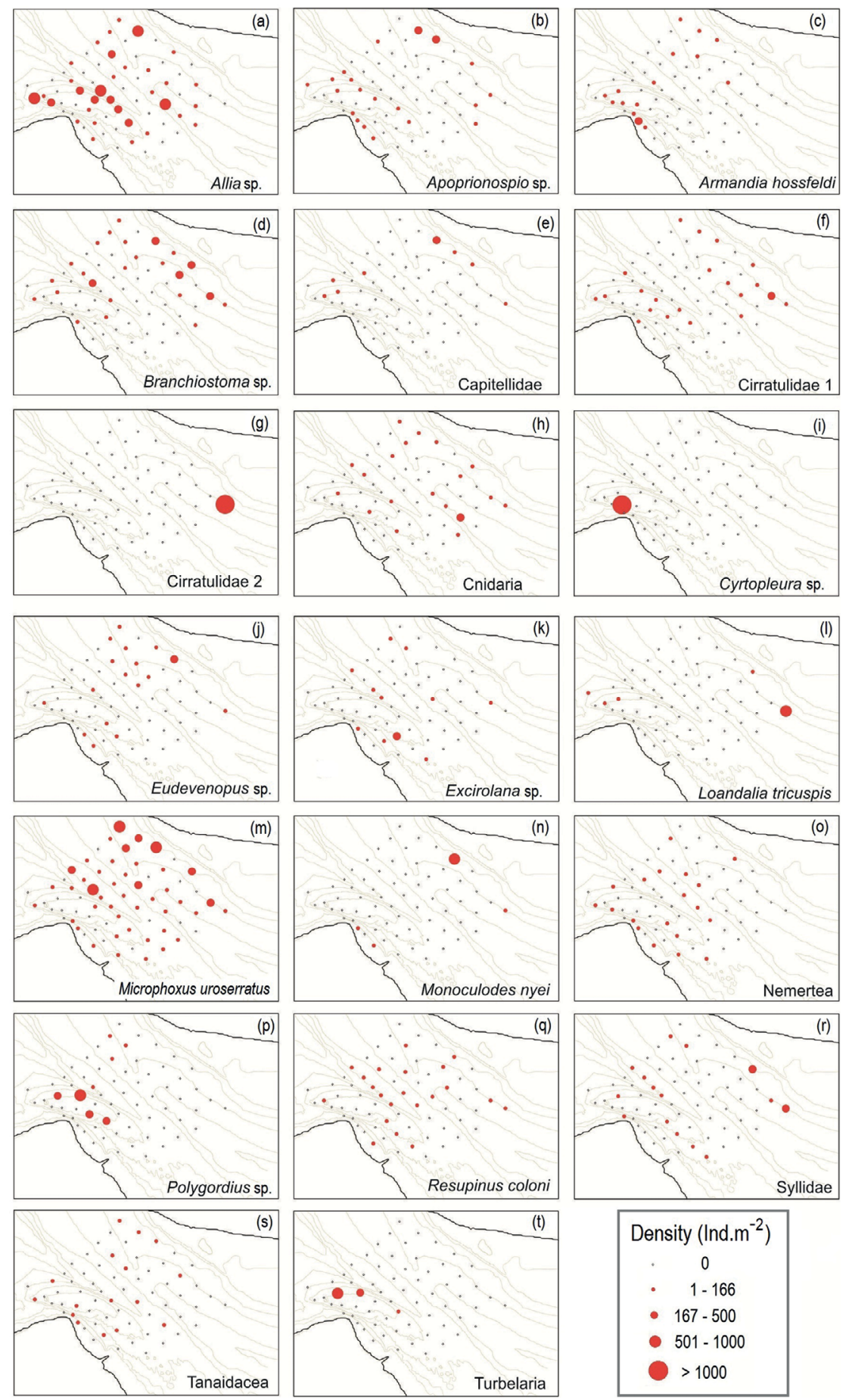

Figure 8. Spatial distribution of the density of the 20 most representative taxa at the Paranaguá Bay inlet, Paraná State, Southern Brazil. 
effort evenly, covering most sources of unknown benthoscape heterogeneity (Cuff and Coleman, 1979; Baudo, 1990).

\section{A NOTE ON THE NATURE OF MAPPING SUBTIDAL} HABITATS

The descriptive nature of mapping habitats does not necessarily fit into the hypothetico-deductive scientific framework. This study suggests that it is primarily an inductive endeavor, in which hypothesis (or hypothetical distribution of subtidal habitats) is construed on diverse sources of data. Testing a specific hypothesis is not a requirement in this framework, though it might be interesting a posteriori, that is, after mosaics of habitats are defined and delimited, an experimental approach could test their validity in a hypothetico-deductive way.

\section{CONCLUSIONS}

Although the mapping of habitats at subsurface reliefs poses substantial challenges, new information was obtained on the Paranaguá Bay inlet. The intrinsic estuarine bottom heterogeneity was evidenced at the landscape scale, and specific regions of higher species richness and density were delineated. Sidescan sonar technology was demonstrated to be an indispensable tool for charting seafloor features, which might be paramount towards estuarine ecosystem functioning and conservation approaches. The present effort was a first step towards understanding local processes of both bottom sediments dynamics and their associate faunal components.

\section{ACKNOWLEDGMENTS}

This project was funded by the Conselho Nacional de Desenvolvimento Científico e Tecnológico (CNPq), granted to O. A. Negrello Filho (158812/2012-3). We thank the Laboratório de Estudos Sedimentológicos (LabSed) and Daniel Paredes for sediment granulometric analysis. We are also grateful to Humberto Gerum (Betão) and Daphne Alves for aiding in fieldwork and helping to develop a sled prototype for filming underwater. An anonymous reviewer offered valuable advice, and the manuscript improved substantially.

\section{REFERENCES}

BAUDO, R. 1990. Sediment sampling, mapping, and data analysis. In: BAUDO, R., GIESY, J. P., MUNTAU, H. (eds.) Sediments: Chemistry and Toxicity of In-Place Pollutants. Ann Arbour: Lewis Publishers. p. 15-60.
BRAECKMAN, U., PROVOOST, P., GRIBSHOLT, B., VAN GANSBEKE, D., MIDDELBURG, J. J., SOATAERT, K., VINX, M. \& VANAVERBEKE, J. 2010. Role of macrofauna functional traits and density in biogeochemical fluxes and bioturbation. Marine Ecology Progress Series, 399, 173-186.

BRIGGS, K. B., WILLIAMS, K. L., JACKSON, D. R., JONES, C. D., IVAKIN, A. N. \& ORSI, T. H. 2002. Fine-scale sedimentary structure: Implications for acoustic remote sensing. Marine Geology, 182, 141-159.

BROWN, C. J. \& COLLIER, J. S. 2008. Mapping benthic habitat in regions of gradational substrata: an automated approach utilizing geophysical, geological, and biological relationships. Estuarine, Coastal and Shelf Science, 78, 203-214.

BROWN, C. J., SMITH, S. J., LAWTON, P. \& ANDERSON, J. T. 2011. Benthic habitat mapping: A review of progress towards improved understanding of the spatial ecology of the seafloor using acoustic techniques. Estuarine, Coastal and Shelf Science, 92, 502-520.

CARVER, R. E. 1971. Procedures in sedimentary petrology, New York, Wiley Interscience.

CLARKE, K. R. 1993. Non-parametric multivariate analyses of changes in community structure. Australian Journal of Ecology, 18, 117-143.

COLLIER, J. S. \& BROWN, C. J. 2005. Correlation of sidescan backscatter with grain size distribution of surficial seabed sediments. Marine Geology, 214, 431-449.

COSTELLO, M. J. 2009. Distinguishing marine habitat classification concepts for ecological data management. Marine Ecology Progress Series, 397, 253-268.

CRAIN, C. M. \& BERTNESS, M. D. 2006. Ecosystem engineering across environmental gradients: implications for conservation and management. BioScience, 56, 211-218.

CUFF, W. \& COLEMAN, N. 1979. Optimal survey design: lessons from a stratified random sampling of macrobenthos. Journal of the Fisheries Research Board of Canada, 36, 351-361.

DE BACKER, A., VAN COILLIE, F., MONTSERRAT, F., PROVOOST, P., VAN COLEN, C., VINCX, M. \& DEGRAER, S. 2011. Bioturbation effects of Corophium volutator: Importance of density and behavioral activity. Estuarine, Coastal and Shelf Science, 91, 306-313.

DIAZ, R. J., SOLAN, M. \& VALENTE, R. M. 2004. A review of approaches for classifying benthic habitats and evaluating habitat quality. Journal of Environmental Management, 73, 165-181.

FERRINI, V. L. \& FLOOD, R. D. 2006. The effects of fine-scale surface roughness and grain size on $300 \mathrm{kHz}$ multibeam backscatter intensity in sandy marine sedimentary environments. Marine Geology, 228, 153-172.

FOLK, R. L. \& WARD, W. C. 1957. Brazos River bar: a study in the significance of grain size parameters. Journal of Sedimentary Petrology, 27, 3-26.

FOLK, R. L. 1965. Petrology of Sedimentary Rocks, Austin, Hemphill Publishing Company.

HEWITT, J. E., THRUSH, S. F., LEGENDRE, P., FUNNELL, G. A., ELLIS, J. \& MORRISON, M. 2004. Mapping of marine soft-sediment communities: integrated sampling for ecological interpretation. Ecological Applications, 14, 12031216. 
HOOPER, D. U., CHAPIN III, F. S., EWEL, J. J., HECTOR, A., INCHAUSTI, P., LAVOREL, J. H., LAWTON, J. H., LODGE, D. M., LOREAU, M., NAEEM, S., SCHMID, B., SETÄLÄ, H., SYMSTAD, A. J., VANDERMEER, J. \& WARDLE, D. A. 2005. Effects of biodiversity on ecosystem functioning: a consensus of current knowledge. Ecological Monographs, 75, 3-35.

KOSTYLEV, V. E., TODD, B. J., FADER, G. B. J., COURTNEY, R. C., CAMERON, G. D. M. \& PICKRILL, R. A. 2001. Benthic habitat mapping on the Scotian Shelf based on multibeam bathymetry, surficial geology and seafloor photographs. Marine Ecology Progress Series, 219, 121-137.

KÜNITZER, A., BASFORD, D., CRAEYMEERSCH, J. A., DEWARUMEZ, J. M., DÖRJES, J., DUINEVELD, G. C. A., ELEFTHERIOU, A., HEIP C., HERMAN, P., KINGSTON, P., NIERMANN, U., RACHOR, E. RUMOHR, H. \& DE WILDE, P. A. J. 1992. The benthic infauna of the North Sea: species distribution and assemblages. ICES Journal of Marine Science: Journal du Conseil, 49, 127-143.

LANA, P. C., MARONE, E., LOPES, R. M. \& MACHADO, E. C. 2000. The subtropical estuarine complex of Paranaguá Bay, Brazil. In: SEELIGER, U. \& KJERFVE, B (eds.) Coastal Marine Ecosystems of Latin America. Heidelberg: Springer-Verlag Berlin. p. 131-145.

MERMILLOD-BLONDIN, F. \& ROSENBERG, R. 2006. Ecosystem engineering: the impact of bioturbation on biogeochemical processes in marine and freshwater benthic habitats. Aquatic Sciences, 68, 434-442.

MILLIMAN, J. D. 1974. Marine carbonates, New York, Springer.
NEGRELLO FILHO, O. A., UNDERWOOD, A. J. \& CHAPMAN, M. G. 2006. Recolonization of infauna on a tidal flat: an experimental analysis of modes of dispersal. Journal of Experimental Marine Biology and Ecology, 328, 240-250.

NOERNBERG, M. A., LAUTERT, L. F. C., ARAÚJO, A. D. \& ODRESKY, L. L. 1997. Base de dados digital do litoral paranaense em sistema de informações geográficas. Nerítica, 11, 191-195.

NOERNBERG, M. A., MARONE, E. \& ANGULO, R. J. 2007. Coastal currents and sediment transport in Paranaguá estuary complex navigation channel. Boletim Paranaense de Geociências, 60-61, 45-54.

SHUMCHENIA, E. J. \& KING, J. W. 2010. Comparison of methods for integrating biological and physical data for marine habitat mapping and classification. Continental Shelf Research, 30, 1717-1729.

SNELGROVE, P. V. R. \& BUTMAN, C. A. 1994. Animal-sediment relationships revisited: cause versus effect. Oceanography and Marine Biology: An Annual Review, 32, 111-177.

THRUSH, S. F. \& LOHRER, A. M. 2012. Why bother going outside: the role of observational studies in understanding biodiversity-ecosystem function relationships. In: SOLAN, M., ASPDEN, J. R. \& PATERSON, D. M. (eds.) Marine Biodiversity and Ecosystem Functioning: Frameworks, methodologies, and integration. Oxford: Oxford University Press. $245 \mathrm{p}$.

ZAJAC, R. N. 2008. Challenges in marine, soft-sediment benthoscape ecology. Landscape Ecology, 23, 7-18. 